\title{
Quantifying Knowledge of Alzheimer's Disease: An Analysis of the Psychometric Properties of the Alzheimer's Disease Knowledge Scale
}

\author{
Guillermo Garcia-Ribas · Elena García-Arcelay (D) · Alonso Montoya • \\ Jorge Maurino · Javier Ballesteros
}

Received: November 16, 2020 / Accepted: January 6, 2021 / Published online: January 29, 2021

(C) The Author(s) 2021

\begin{abstract}
Introduction: The Alzheimer's Disease Knowledge Scale (ADKS) is one of the most popular instruments for assessing a person's knowledge regarding Alzheimer's disease (AD). The objective of this study was to explore ADKS item characteristics with item response theory (IRT) procedures.

Methods: A noninterventional web-based study was conducted. A nonparametric IRT procedure, Mokken analysis, was used to explore the underlying latent structure of the ADKS and ADKS item characteristics regarding scalability and violations of the monotone homogeneity (MH) model. A random-effects meta-analysis was implemented that combined ADKS scores from independent studies.
\end{abstract}

G. Garcia-Ribas

Department of Neurology, Hospital Universitario Ramón Y Cajal, Madrid, Spain

E. García-Arcelay $(\bowtie) \cdot J$. Maurino

Medical Department, Roche Farma, Madrid, Spain

e-mail: elena.garcia_arcelay.eg1@roche.com

A. Montoya

Medical Affairs, Neuroscience, Hoffmann-La Roche

Limited, Mississauga, ON, Canada

J. Ballesteros

Department of Neurosciences and CIBERSAM,

University of the Basque Country, Leioa, Spain
Results: A total of 447 employees of a pharmaceutical company participated in the study. The mean ADKS score was 21.2 (SD 2.8). Mokken analysis showed that most ADKS items (22 of 30) do not fit to any scale and can be considered to be scale independent. Two items (\#1: particularly prone to depression; \#20: depression can be mistaken for AD) fit to a domain relating to depression, another two items (\#2: mental exercise can prevent $\mathrm{AD}$ development; \#8: benefit of psychotherapy) can be related to potential prevention and improvement, and four items (\#12: poor nutrition can make the symptoms worse; \#18: high cholesterol may increase the risk of $\mathrm{AD}$; \#26: high blood pressure may increase the risk of $\mathrm{AD}$; \#27: genes can only partially account for AD development) fit to a risk factor domain. As expected from those results, neither the overall scale $(H=0.033)$ nor its items showed appropriate scalability index values, suggesting that ADKS does not fit to a $\mathrm{MH}$ model. Eleven items showed violations of the assumptions of the $\mathrm{MH}$ model. The metaanalytical average score was 21.78 (95\% CI 20.67-22.90), with healthcare professionals and caregivers showing the highest levels of $\mathrm{AD}$ knowledge.

Conclusion: Although the ADKS does not present a unidimensional structure, its independent items together provide a comprehensive spectrum of information regarding $\mathrm{AD}$ knowledge. 
Keywords: Alzheimer's disease; Alzheimer's Disease Knowledge Scale; Knowledge; Psychometric assessment

\section{Key Summary Points}

\section{Why carry out this study?}

Lack of knowledge and misconceptions about Alzheimer's disease are critical problems around the world.

Improving the public's understanding of Alzheimer's disease may facilitate early diagnosis, reduce stigma about the disease, and prompt a discussion of the needs of patients and their families.

\section{What was learned from the study?}

The Alzheimer's Disease Knowledge Scale is a self-rated questionnaire that assesses what people know about Alzheimer's disease in different key domains. In addition to its good psychometric properties, it is an easy-to-implement and reliable tool for evaluating knowledge gaps in laypersons, caregivers, and healthcare professionals.

\section{DIGITAL FEATURES}

This article is published with digital features, including a summary slide, to facilitate understanding of the article. To view digital features for this article go to https://doi.org/10.6084/ m9.figshare.13526369.

\section{INTRODUCTION}

Alzheimer's disease (AD) leads to irreversible progressive cognitive impairment. It is the most common type of dementia, affecting millions of people worldwide $[1,2]$.

Although information about cognitive impairment has been widely disseminated through numerous awareness campaigns and educational programs, several studies have revealed different gaps in the public's knowledge regarding dementia and $\mathrm{AD}$ [3-6]. Adequate $\mathrm{AD}$ knowledge throughout society could lead to earlier identification of this disorder in the population, which would result in earlier appropriate healthcare for people with dementia and would decrease the stigma associated with $\mathrm{AD}$ [3]. In addition, understanding people's perceptions of $\mathrm{AD}$ can be crucial when carrying out specific psychosocial intervention strategies [3].

Various instruments have been developed to assess knowledge of dementia and $\mathrm{AD}$, including the Alzheimer's Disease Knowledge Test (ADKT), the University of Alabama Alzheimer's Disease Knowledge Test for Health Professionals (UAB-ADKT), the Dementia Quiz (DQ), the Knowledge about Memory Loss and Care test (KAML-C), the Alzheimer's Disease Knowledge Scale (ADKS), the Dementia Knowledge Assessment Tool Version 2 (DKAT2), the Dementia Knowledge 20 (DK-20), and the University of Jaén Alzheimer's Care Scale (UJA ACS) [7-9].

The ADKS is one of the most widely used of these instruments [3]. It is a 30-item questionnaire that measures what people know about $\mathrm{AD}$ across seven critical knowledge domains: risk factors (six items), symptoms (4 items), assessment and diagnosis (4 items), disease trajectory (4 items), life impact (3 items), treatment and management (4 items), and caregiving (5 items) [10]. The ADKS has adequate psychometric properties and is designed to be administered to the general public, patients, caregivers, and healthcare professionals $[8,10]$.

We aimed to achieve a greater understanding of the psychometric characteristics of the ADKS by applying nonparametric item response theory (IRT) procedures to the responses obtained from an anonymous survey. To our knowledge, this is the first time that a study has focused on ADKS item characteristics instead of using classical approaches that rely on the reliability and validity of the total ADKS score. 


\section{METHODS}

\section{Study Design and Participants}

A noninterventional, cross-sectional, self-completed, web-based study (the CONOCE study) was conducted among employees of a pharmaceutical company in Spain (Roche Farma SA). This study was conducted in accordance with the Good Clinical Practice Guidelines of the International Conference on Harmonisation and with the ethical principles of the Declaration of Helsinki. It was approved by the investigational review board of the Hospital Universitario Ramón y Cajal, Madrid, Spain (reference code: 372). Informed consent was obtained from all subjects. Participants were invited to participate from December 2019 to February 2020.

\section{Study Procedures}

Participants answered questions regarding demographic data and completed the ADKS. Each ADKS item is a statement that can be either false (value 0) or true (value 1) [10]. "True" is the correct response for 18 items, whereas the remaining 12 items are reverse scored, so "false" is the correct response for those items. A higher score indicates better knowledge regarding $\mathrm{AD}$.

\section{Statistical Analyses}

Continuous variables were described using means and standard deviations, and categorical variables using frequencies and percentages. A nonparametric IRT procedure-Mokken analysis-was used to explore the underlying measurement structure of the ADKS and how well it fits to the monotone homogeneity $(\mathrm{MH})$ model, which allows people to be ranked on $\mathrm{AD}$ knowledge based on their total ADKS scores. Among other criteria, the MH model assumes unidimensionality of the latent construct measured with the scale, as assessed with Loevinger's scalability coefficients [11]. Scalability coefficients describe the degree to which individual items $\left(H_{i}\right)$, pairs of items $\left(H_{i j}\right)$, and the overall set of items $(H)$ form a scale that can be used to rank people on their ability (knowledge) regarding the latent trait being measured (AD knowledge). Scalability coefficients reflect the ratio of the observed Guttman error frequency (inadequacy with which the achievement level is matched to the difficulty of the item being measured) to the expected Guttman error frequency (i.e., based on chance alone) for a pair of items $[12,13]$. When data fit well to the $\mathrm{MH}$ model, $H_{i}$ values are positive and range from zero to 1 , where a value of 1 indicates no Guttman errors and values closer to zero indicate many Guttman errors. To define an appropriate unidimensional scale, each one of the 30 ADKS items was required to have a scalability coefficient $\left(H_{i}\right)$ of $\geq 0.30$ and an overall scale scalability index $(H)$ of $\geq 0.30$ [14]. We extracted the published effect sizes of the ADKS from previous studies (mean values, standard deviations, and sample sizes) and combined them with our own results using a random-effects meta-analysis to arrive at an estimate of the overall $\mathrm{AD}$ knowledge and how this knowledge differed between population subgroups [15].

We performed the statistical analyses with $\mathrm{R}$ version 4.0 (https://cran.r-project.org/) using the libraries "mokken" for IRT and "metafor" for the random-effects meta-analysis [11, 16, 17].

\section{RESULTS}

A total of 447 subjects participated in the study. Most participants were aged between 18 and 50 years $(78 \%)$, female $(65 \%)$, and had a bachelor's or master's degree (89\%). Forty-two (9.4\%) participants reported having a first-degree relative with AD. Demographic characteristics of the sample are shown in Table 1.

\section{Overall AD Knowledge}

The mean ADKS score was 21.2 (SD 2.8; 95\% CI 20.9-21.4). For four items (caregiving domain: "informed decisions" and "difficulties with selfcare;" risk factors domain: "at risk for high blood pressure" and "at risk for high cholesterol"), less than $50 \%$ of the answers were 
Table 1 Demographic characteristics of the study sample $(n=447)$

\begin{tabular}{lrr}
\hline & $n$ & $\%$ \\
\hline Gender & 292 & 65.3 \\
Female & & \\
Age, years & 66 & 14.8 \\
$\leq 30$ & 113 & 25.3 \\
$31-40$ & 170 & 38.0 \\
$41-50$ & 93 & 20.8 \\
$51-60$ & 5 & 4.7 \\
$>60$ & & \\
Education & 23 & 5.1 \\
Secondary & 26 & 5.8 \\
Vocational training & 167 & 37.4 \\
Bachelor's degree or equivalent & 203 & 45.4 \\
Master's degree or equivalent & 28 & 6.3 \\
PhD or equivalent & 42 & 9.4 \\
AD caregiver & & \\
\hline
\end{tabular}

$A D$ Alzheimer's disease

correct. Figure 1 shows the ADKS items ranked by percentage of correct answers ("percent correct") after reversing the scores for inverse items.

Figure 2 shows the frequency distribution of scores along the observed range (13-29 points); $50 \%$ of the observations occur between the score values of 19 and 23 (which therefore correspond to the $25 \%$ and $75 \%$ percentiles of the ADKS score distribution, respectively).

\section{Underlying Structure of the ADKS and Item Characteristics}

Most of the ADKS items (22 of 30) do not fit to any scale and can be considered to be scale independent. Two items (\#1 and \#20) fit to a knowledge domain related to depression, another two items ( \#2 and \#8) are related to AD prevention and recovery, and four items (\#12,
\#18, \#26, and \#27) fit to a knowledge domain related to risk factors. Table 2 shows the results of the automated item selection procedure (AISP) that was implemented to ascertain the knowledge domains covered by the ADKS in the current survey.

As expected from those results, neither the overall scale $(H=0.033)$ nor its items showed appropriate scalability indices. No item had a scalability index $H_{i} \geq 0.30$, and indices were in fact quite low, suggesting that the ADKS does not fit a $\mathrm{MH}$ model. Moreover, 11 items violated assumptions of the MH model (Table 2).

\section{Meta-analysis of the ADKS Scores}

Table 3 shows the main characteristics and effect sizes of the studies that have reported ADKS mean scores (including the present study). Figure 3 displays a forest plot with individual and combined ADKS scores. The combined result has a relatively high mean score (mean 21.78; 95\% CI 20.67-22.90) that differs significantly among subgroups $(Q$ test $=11.35$ on $4 \mathrm{df} ; p$ value $=0.02$ ), with health professionals presenting the highest mean score (11 data points, mean ADKS $=22.9$ ), followed closely by caregivers ( 3 data points, mean ADKS = 21.6). A study conducted by Baral et al. found that students obtained the lowest scores (ADKS score $=15.4$ ), whereas the subgroup of health professionals yielded the highest scores in a study by Carpenter et al. (ADKS score $=27.4$ ) $[10,18]$.

\section{DISCUSSION}

The ADKS belongs to a group of psychometric scales that aim to assess knowledge regarding $\mathrm{AD}$, as this can assist with the development of psychoeducational curricula and interventions for dementia care [7]. The original validation of the ADKS included different populations in the USA (college students, older adults with no cognitive impairment, dementia caregivers, and healthcare professionals), and the scale was also applied to or validated by studying college students in South Korea and Nepal, caregivers in the Netherlands, the United Kingdom, and 


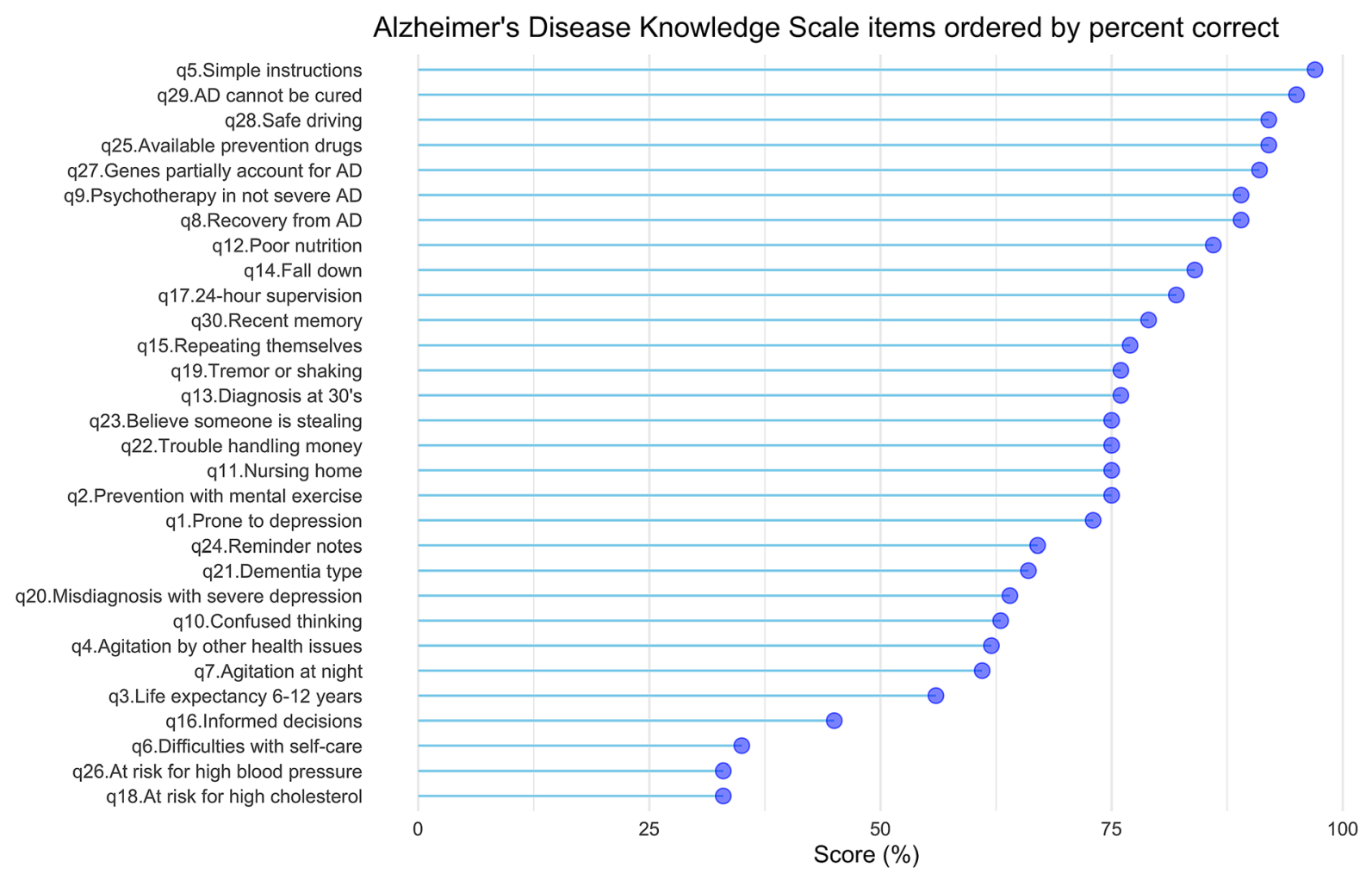

Fig. 1 Alzheimer's Disease Knowledge Scale: correct answers

South Korea, and healthcare professionals in Australia, Brazil, China, India, Malaysia, and Spain [8, 10, 18-27]. It was also administered to laypeople in Brazil, and was included as a knowledge resource on the website of the Alzheimer's Association in the USA $[26,28]$.

Despite some criticisms of the ADKS that are linked to dichotomous item assessment, reverse-scored items, and a likely ceiling effect for some items, this is currently one of the few validated scales to be used either at the intervention planning stage or as a signal or outcome measure when evaluating interventions or the overall knowledge of dementia [7, 8, 29]. Because the ADKS was designed to estimate the overall knowledge regarding $\mathrm{AD}$, not an underlying construct or dimension, several common psychometric statistics such as internal reliability or analyses of dimensional structure are not as relevant as they might be to other scales that are used to evaluate the effectiveness of interventions [7, 8].

Our study shows that the range of percent correct values for ADKS items and the near- symmetric distribution of overall scores may support its usefulness for relatives of people with cognitive impairment who are seeking a neurological evaluation, and to guide the psychoeducational efforts of dementia support groups [10]. However, the results of the IRT approach do not support scale unidimensionality or the ranking of subjects across a continuum of AD knowledge. The AISP indicates that the underlying structure of the ADKS does not fit the originally theorized domains. It instead suggests that items are independent, which is relevant for a general knowledge scale that is used to detect knowledge gaps, but not for ranking individuals.

Carpenter et al. [10] developed the ADKS in 2009 to incorporate new scientific understanding about $\mathrm{AD}$ into the ADKT. All measures require periodic updates to keep pace with developments and new information emerging from the rapidly evolving field of cognitive disorders. In their systematic review of $\mathrm{AD}$ knowledge outcome measures, Spector et al. recommend the development of a 
Alzheimer's Disease Knowledge Scale (range 0 to 30 )

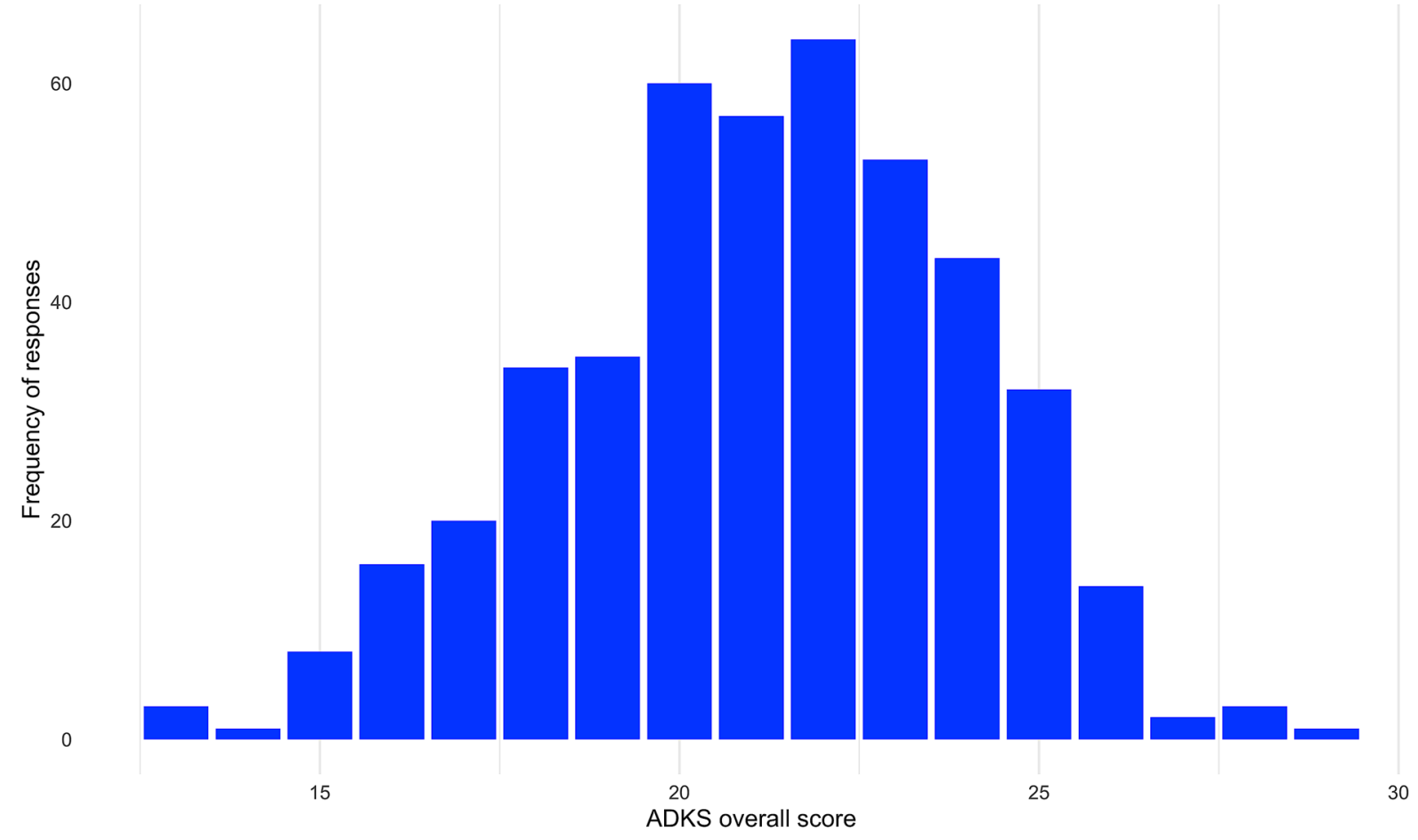

Fig. 2 Alzheimer's Disease Knowledge Scale: distribution of scores

contemporary instrument that incorporates items relating to biopsychosocial and patientcentered models of AD care [7]. Our results do not support the use of the total ADKS score to meaningfully rank people according to their $\mathrm{AD}$ knowledge, as the data did not fit with the $\mathrm{MH}$ model. However, even though the IRT results indicate that the ADKS is not suitable for evaluating people at the individual level, it does not directly follow that group mean scores based on knowledge accrued from multiple independent items are not suitable for comparing population subgroups in terms of their AD knowledge, as our meta-analytical results show. In fact, what might be argued is that the ADKS is a useful outcome measure for evaluating the effectiveness of interventions. When Hattink et al. evaluated an e-learning course for dementia caregivers, they did not find a significant difference between subjects randomized to the experimental psychoeducational intervention $(n=37$, mean ADKS score $=24.37, \mathrm{SD}=2.94)$ and those randomized to the control intervention $(n=46$, mean ADKS score $=24.39, \mathrm{SD}=$
2.90) [20]. The mean difference (MD) was not significantly different between groups (MD $-0.02,95 \%$ CI -1.30 to 1.26 ) and did not show a significant change at four months from baseline $(n=83$, mean ADKS score $=24.28$, $\mathrm{SD}=3.35$ ). However, even given the serious doubts regarding the use of ADKS as an outcome measure to evaluate interventions, knowledge of the correctness of responses may be useful when designing and developing interventions aimed at improving $\mathrm{AD}$ knowledge among caregivers and health professionals-aims that also guided the development of the ADKS [10].

This study has several limitations. There is participant self-selection bias; it is possible that the survey tended to attract the most motivated respondents or those who were most knowledgeable about $\mathrm{AD}$. In addition, carrying out the study in only one company may have limited the generalizability of the findings to other healthcare communities, or even the general population. 
Table 2 Correct answers, results from the Mokken automated item selection procedure, scalability coefficients, and monotone homogeneity model violation counts for the Alzheimer's Disease Knowledge Scale $(n=447)$

\begin{tabular}{|c|c|c|c|c|}
\hline Item no. and wording & $\begin{array}{l}\text { Correct } \\
\text { answers } \\
n(\%)\end{array}$ & AISP & $\begin{array}{l}\text { Scalability } \\
\text { coefficient }\end{array}$ & $\begin{array}{l}\text { No. of } \\
\text { significant } \\
\text { violations }\end{array}$ \\
\hline 1. People with $\mathrm{AD}$ are particularly prone to depression & $327(73)$ & 3 & 0.057 & 0 \\
\hline $\begin{array}{l}\text { 2. It has been scientifically proven that mental exercise can prevent a } \\
\text { person from getting AD }\end{array}$ & $334(75)$ & 2 & 0.047 & 1 \\
\hline $\begin{array}{l}\text { 3. After symptoms of } \mathrm{AD} \text { appear, the average life expectancy is } \\
6-12 \text { years }\end{array}$ & $249(56)$ & 0 & 0.015 & 0 \\
\hline $\begin{array}{l}\text { 4. When a person with } \mathrm{AD} \text { becomes agitated, a medical examination } \\
\text { might reveal other health problems that caused the agitation }\end{array}$ & $277(62)$ & 0 & -0.006 & 1 \\
\hline $\begin{array}{l}\text { 5. People with } \mathrm{AD} \text { do best with simple instructions, giving one step } \\
\text { at a time }\end{array}$ & $432(97)$ & 0 & 0.003 & 1 \\
\hline $\begin{array}{l}\text { 6. When people with } \mathrm{AD} \text { begin to have difficulty taking care of } \\
\text { themselves, caregivers should take over right away }\end{array}$ & $156(35)$ & 0 & 0.045 & 1 \\
\hline $\begin{array}{l}\text { 7. If a person with } \mathrm{AD} \text { becomes alert and agitated at night, a good } \\
\text { strategy is to try to make sure that the person gets plenty of } \\
\text { physical activity during the day }\end{array}$ & $274(61)$ & 0 & -0.004 & 1 \\
\hline 8. In rare cases, people have recovered from $\mathrm{AD}$ & $398(89)$ & 2 & -0.002 & 2 \\
\hline $\begin{array}{l}\text { 9. People whose } \mathrm{AD} \text { is not yet severe can benefit from psychotherapy } \\
\text { for depression and anxiety }\end{array}$ & $398(89)$ & 0 & 0.054 & 1 \\
\hline $\begin{array}{l}\text { 10. If trouble with memory and confused thinking appears suddenly, } \\
\text { it is likely due to } \mathrm{AD}\end{array}$ & $283(63)$ & 0 & 0.019 & 0 \\
\hline 11. Most people with $\mathrm{AD}$ live in nursing homes & $334(75)$ & 0 & -0.008 & 1 \\
\hline 12. Poor nutrition can make the symptoms of $\mathrm{AD}$ worse & $385(86)$ & 1 & 0.073 & 0 \\
\hline 13. People in their 30 s can have $\mathrm{AD}$ & $341(76)$ & 0 & 0.039 & 0 \\
\hline $\begin{array}{l}\text { 14. A person with } \mathrm{AD} \text { becomes increasingly likely to fall down as the } \\
\text { disease gets worse }\end{array}$ & $377(84)$ & 0 & 0.031 & 0 \\
\hline $\begin{array}{l}\text { 15. When people with } \mathrm{AD} \text { repeat the same question or story several } \\
\text { times, it is helpful to remind them that they are repeating } \\
\text { themselves }\end{array}$ & $343(77)$ & 0 & 0.034 & 0 \\
\hline $\begin{array}{l}\text { 16. Once people have } \mathrm{AD} \text {, they are no longer capable of making } \\
\text { informed decisions about their own care }\end{array}$ & $203(45)$ & 0 & 0.063 & 0 \\
\hline 17. Eventually, a person with $\mathrm{AD}$ will need $24 \mathrm{~h}$ supervision & $365(82)$ & 0 & 0.006 & 1 \\
\hline $\begin{array}{l}\text { 18. Having high cholesterol may increase a person's risk of } \\
\text { developing AD }\end{array}$ & $149(33)$ & 1 & 0.092 & 0 \\
\hline $\begin{array}{l}\text { 19. Tremor or shaking of the hands or arms is a common symptom } \\
\text { in people with } \mathrm{AD}\end{array}$ & $340(76)$ & 0 & -0.006 & 3 \\
\hline
\end{tabular}


Table 2 continued

Item no. and wording

20. Symptoms of severe depression can be mistaken for symptoms of 288 (64) $\mathrm{AD}$

21. $\mathrm{AD}$ is one type of dementia

22. Trouble handling money or paying bills is a common early symptom of $\mathrm{AD}$

23. One symptom that can occur with $\mathrm{AD}$ is believing that other people are stealing one's things

24. When a person has $\mathrm{AD}$, using reminder notes is a crutch that can contribute to decline

25. Prescription drugs that prevent AD are available

26. Having high blood pressure may increase a person's risk of developing $\mathrm{AD}$

27. Genes can only partially account for the development of AD

28. It is safe for people with $\mathrm{AD}$ to drive as long as they have a companion in the car at all times

29. AD cannot be cured

30. Most people with $\mathrm{AD}$ remember recent events better than things that happened in the past

\section{Correct \\ answers \\ $n(\%)$}

$\begin{array}{rrrr}297(66) & 0 & -0.002 & 0 \\ 335(75) & 0 & 0.048 & 0\end{array}$
AISP Scalability coefficient
No. of significant violations

3

0.060

0

0

0

$334(75) \quad 0 \quad 0.075 \quad 0$

$\begin{array}{llll}301(67) & 0 & 0.038 & 0\end{array}$

$410(92) \quad 0 \quad 0.015 \quad 0$

$149(33) \quad 1 \quad 0.064 \quad 0$

$409(92) \quad 1 \quad 0.098 \quad 0$

$\begin{array}{llll}412(92) & 0 & 0.005 & 1\end{array}$

$\begin{array}{llll}424(95) & 0 & 0.052 & 0 \\ 354(79) & 0 & 0.033 & 0\end{array}$

An AISP value of zero denotes an item that does not fit to any scale

$A D$ Alzheimer's disease, AISP automated item selection procedure, $M H$ monotone homogeneity

\section{CONCLUSION}

Lack of information and misconceptions about $\mathrm{AD}$ are still critical problems. Whereas the ADKS does not show the characteristics and dimensionality expected of a scale whose aim is to evaluate a nonobservable latent factor or construct, it does present a set of items that together contribute to the overall knowledge of $\mathrm{AD}$, and so it might be useful for evaluating knowledge gaps regarding $\mathrm{AD}$. As originally described, the ADKS can be used with laypeople or caregivers to determine what they know about $\mathrm{AD}$, and by healthcare professionals and support groups to guide psychoeducational efforts. 
Table 3 Average Alzheimer's Disease Knowledge Scale scores for different populations

\begin{tabular}{|c|c|c|c|c|}
\hline Study and year & Country & Population & $n$ & Mean ADKS (SD) \\
\hline \multirow[t]{5}{*}{ Carpenter $[10]$} & \multirow[t]{5}{*}{ USA } & Students & 484 & $20.19(3.59)$ \\
\hline & & Older adults with no cognitive impairment & 89 & $24.10(2.95)$ \\
\hline & & Senior center staff & 61 & $20.15(4.10)$ \\
\hline & & Dementia caregivers & 54 & $22.70(4.27)$ \\
\hline & & Healthcare professionals & 75 & $27.40(1.89)$ \\
\hline Nordhus [19] & Norway & Psychologists & 956 & $24.10(2.50)$ \\
\hline Smyth [22] & Australia & Healthcare professionals & 360 & $23.60(3.26)$ \\
\hline Hattink [20] & Netherlands and UK & Dementia caregivers & 83 & $24.28(3.35)$ \\
\hline Hughes [28] & USA & Alzheimer's Association website visitors & 552 & $23.11(3.36)$ \\
\hline \multirow[t]{3}{*}{ Kim $[21]$} & \multirow[t]{3}{*}{ South Korea } & Students & 422 & $19.29(2.93)$ \\
\hline & & Healthcare professionals & 64 & $21.56(2.61)$ \\
\hline & & Dementia caregivers & 89 & $17.93(2.88)$ \\
\hline Mat Nuri [23] & Malaysia & Pharmacists & 445 & $19.05(3.69)$ \\
\hline Sullivan $[8]$ & Australia & Healthcare professionals & 55 & $22.80(2.89)$ \\
\hline \multirow[t]{2}{*}{ Amado [26] } & \multirow[t]{2}{*}{ Brazil } & Laypeople & 899 & $20.50(3.33)$ \\
\hline & & Healthcare professionals & 515 & $23.46(3.51)$ \\
\hline \multirow[t]{2}{*}{ Alacreu [24] } & \multirow[t]{2}{*}{ Spain } & Pharmacists & 578 & $22.95(2.50)$ \\
\hline & & General practitioners & 104 & $24.40(2.30)$ \\
\hline Strom $[25]$ & India & Nurses & 15 & $19.50(3.00)$ \\
\hline Baral [18] & Nepal & Students & 385 & $15.45(2.95)$ \\
\hline Wang [27] & China & General practitioners & 341 & $21.42(2.73)$ \\
\hline This study 2020 & Spain & Roche employees & 447 & $21.16(2.83)$ \\
\hline
\end{tabular}

ADKS Alzheimer's Disease Knowledge Scale, $S D$ standard deviation

\section{ACKNOWLEDGEMENTS}

The authors thank all Roche employees who took their time to complete the survey.

Funding. This study and the journal's Rapid Service Fee were funded by Roche Farma Spain Medical Department.
Authorship. All named authors meet the International Committee of Medical Journal Editors (ICMJE) criteria for authorship for this article, take responsibility for the integrity of the work as a whole, and have given their approval for this version to be published.

Authorship Contributions. All authors made substantial contributions to the conception and design of the study, data acquisition, 


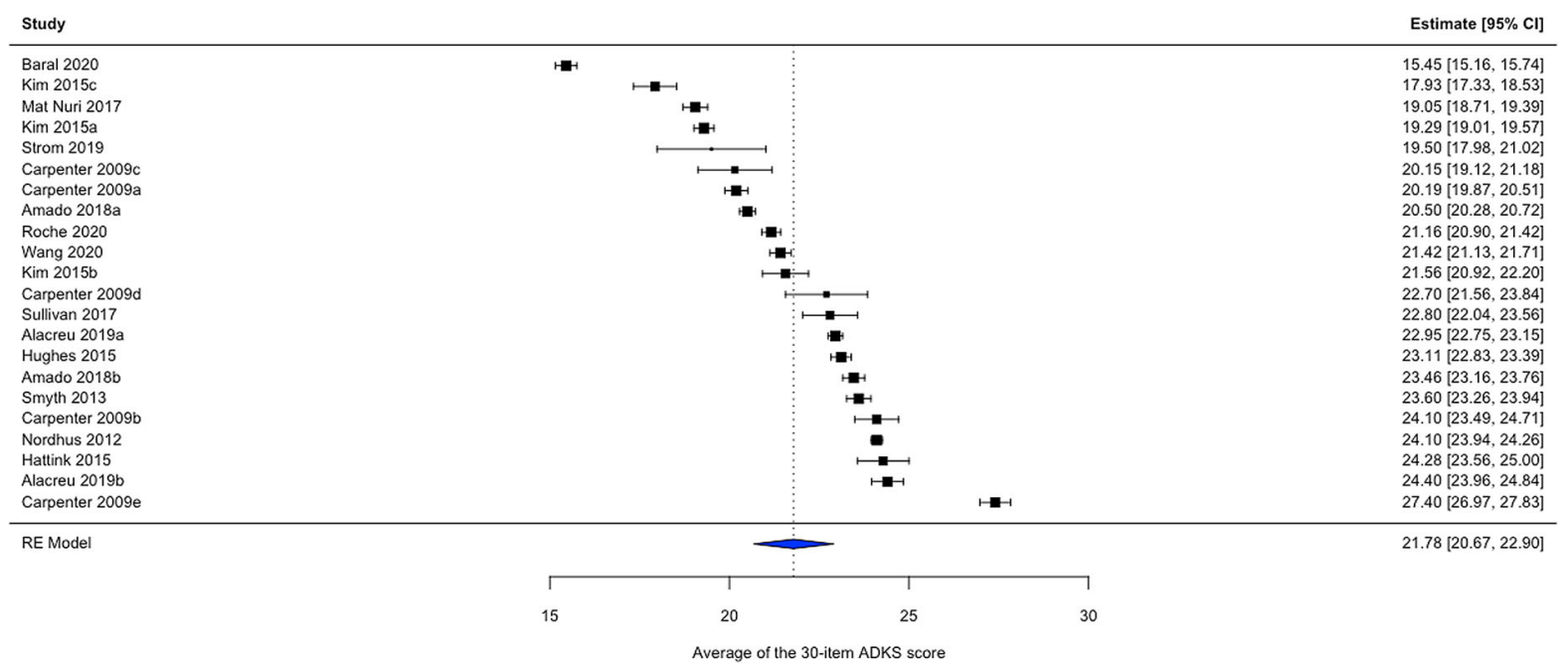

Fig. 3 Meta-analysis of Alzheimer's Disease Knowledge Scale scores

or data analysis and interpretation; took part in drafting the article and revising it critically for important intellectual content; gave final approval of the version to be published; and agree to be accountable for all aspects of the work.

Prior Presentation. The abstract of this paper was presented at the Virtual European Congress of the International Society for Pharmacoeconomics and Outcomes Research (ISPOR) as a poster presentation with interim findings (poster PND63; November 16-19, 2020).

Disclosures. Elena García-Arcelay and Jorge Maurino are employees of Roche Farma Spain. Alonso Montoya is an employee of HoffmannLa Roche Limited, Canada. Guillermo GarciaRibas and Javier Ballesteros report no conflicts of interest.

Compliance with Ethics Guidelines. The CONOCE study was conducted in accordance with the Good Clinical Practice Guidelines of the International Conference on Harmonisation and with the ethical principles of the Declaration of Helsinki. The study was approved by the investigational review board of the Hospital Universitario Ramón y Cajal, Madrid, Spain (reference code: 372). Informed consent was obtained from all subjects.
Data Availability. Qualified researchers may request access to patient-level data through the clinical study data request platform (https:// vivli.org/). Further details on Roche's criteria for eligible studies are available at https://vivli.org/ members/ourmembers/. For further details on Roche's Global Policy on the Sharing of Clinical Information and how to request access to related clinical study documents, see https://www. roche.com/research_and_development/who_ we_are_how_we_work/clinical_trials/our_ commitment_to_data_sharing.htm).

Open Access. This article is licensed under a Creative Commons Attribution-NonCommercial 4.0 International License, which permits any non-commercial use, sharing, adaptation, distribution and reproduction in any medium or format, as long as you give appropriate credit to the original author(s) and the source, provide a link to the Creative Commons licence, and indicate if changes were made. The images or other third party material in this article are included in the article's Creative Commons licence, unless indicated otherwise in a credit line to the material. If material is not included in the article's Creative Commons licence and your intended use is not permitted by statutory regulation or exceeds the permitted use, you will need to obtain permission directly from the copyright holder. To view a copy of this licence, 
visit http://creativecommons.org/licenses/bync/4.0/.

\section{REFERENCES}

1. Kumfor F, Halliday GM, Piguet O. Clinical aspects of Alzheimer's disease. Adv Neurobiol. 2017;15: 31-53.

2. GBD 2016 Dementia Collaborators. Global, regional, and national burden of Alzheimer's disease and other dementias, 1990-2016: a systematic analysis for the Global Burden of Disease Study 2016. Lancet Neurol. 2019;18(1):88-106.

3. Cahill S, Pierce M, Werner P, Darley A, Bobersky A. A systematic review of the public's knowledge and understanding of Alzheimer's disease and dementia. Alzheimer Dis Assoc Disord. 2015;29(3):255-75.

4. Jorge C, Ceto M, Arias A, et al. Level of understanding of Alzheimer disease among caregivers and the general population. Neurologia. 2018 (published online ahead of print)

5. Farina N, Suemoto CK, Burton JK, Oliveira D, Frost R. Perceptions of dementia amongst the general public across Latin America: a systematic review. Aging Ment Health. 2020;1-10.

6. García-Ribas G, García-Arcelay E, Montoya A, Maurino J. Assessing knowledge and perceptions of Alzheimer's disease among employees of a pharmaceutical company in Spain: a comparison of caregivers versus non-caregivers. Patient Prefer Adherence. 2020;14:2357-64.

7. Spector A, Orrell M, Schepers A, Shanahan N. A systematic review of "knowledge of dementia" outcome measures. Ageing Res Rev. 2012;11(1): $67-77$.

8. Sullivan KA, Mullan MA. Comparison of the psychometric properties of four dementia knowledge measures: which test should be used with dementia care staff? Australas J Ageing. 2017;36(1):38-45.

9. Parra-Anguita L, Sánchez-García I, Del Pino-Casado R, Pancorbo-Hidalgo PL. Measuring knowledge of Alzheimer's: development and psychometric testing of the UJA Alzheimer's Care Scale. BMC Geriatr. 2019;19(1):63.

10. Carpenter BD, Balsis S, Otilingam PG, Hanson PK, Gatz M. The Alzheimer's Disease Knowledge Scale: development and psychometric properties. Gerontologist. 2009;49(2):236-47.
11. van der Ark LA. Mokken scale analysis in R. J Stat Softw. 2007;20(11):1-19.

12. Sijtsma K, van der Ark LA. A tutorial on how to do a Mokken scale analysis on your test and questionnaire data. Br J Math Stat Psychol. 2017;70(1): 137-58.

13. Wind SA. An instructional module on mokken scale analysis. Educ Meas Issues Pract. 2017;36(2):50-66.

14. Meijer RR, Sijtsma K, Smid NG. Theoretical and empirical comparison of the Mokken and the Rasch approach to IRT. Appl Psychol Meas. 1990;14(3): 283-98.

15. Hedges LV, Vevea JL. Fixed- and random-effects models in meta-analysis. Psychol Methods. 1998;3(4):486-504.

16. van der Ark LA. New developments in Mokken scale analysis in R. J Stat Softw. 2012;48(5):1-27.

17. Viechtbauer W. Conducting meta-analyses in $\mathrm{R}$ with the metafor package. J Stat Softw. 2010;36(3): $1-48$.

18. Baral K, Dahal M, Pradhan S. Knowledge regarding Alzheimer's disease among college students of Kathmandu. Nepal Int J Alzheimers Dis. 2020;2020: $1-6$.

19. Nordhus IH, Sivertsen B, Pallesen S. Knowledge about Alzheimer's disease among Norwegian psychologists: the Alzheimer's disease knowledge scale. Aging Ment Health. 2012;16(4):521-8.

20. Hattink B, Meiland F, van der Roest H, et al. WebBased STAR e-learning course increases empathy and understanding in dementia caregivers: results from a randomized controlled trial in the Netherlands and the United Kingdom. J Med Internet Res. 2015;17(10):e241.

21. Kim EJ, Jung J. Psychometric properties of the Alzheimer's Disease Knowledge Scale-Korean version. J Korean Acad Nurs. 2015;45(1):107.

22. Smyth W, Fielding E, Beattie E, et al. A survey-based study of knowledge of Alzheimer's disease among health care staff. BMC Geriatr. 2013;13(1):2.

23. Nuri THM, Hong YH, Ming LC, Joffry SM, Othman MF, Neoh CF. Knowledge on Alzheimer's disease among public hospitals and health clinics pharmacists in the state of Selangor, Malaysia. Front Pharmacol. 2017;8:739.

24. Alacreu M, Pardo J, Azorín M, Climent MT, Gasull $\mathrm{V}$, Moreno L. Importance of increasing modifiable risk factors knowledge on Alzheimer's disease 
among community pharmacists and general practitioners in Spain. Front Pharmacol. 2019;10:860.

25. Strøm BS, Engedal K, Andreassen L. Nursing staff's knowledge and attitudes toward dementia: a pilot study from an Indian perspective. Dement Geriatr Cogn Disord Extra. 2019;9(3):352-61.

26. Amado DK, Brucki SMD. Knowledge about Alzheimer's disease in the Brazilian population. Arq Neuropsiquiatr. 2018;76(11):775-82.

27. Wang M, Xu X, Huang Y, et al. Knowledge, attitudes and skills of dementia care in general practice: a cross-sectional study in primary health settings in Beijing, China. BMC Fam Pract. 2020;21(1):1-9.

28. Hughes ML, Lowe DA, Shine HE, Carpenter BD, Balsis S. Using the Alzheimer's Association web site to improve knowledge of Alzheimer's Disease in health care providers. Am J Alzheimers Dis Dementia. 2015;30(1):98-100.

29. Annear MJ, Eccleston CE, McInerney FJ, et al. A new standard in dementia knowledge measurement: comparative validation of the Dementia Knowledge Assessment Scale and the Alzheimer's Disease Knowledge Scale. J Am Geriatr Soc. 2016;64(6): 1329-34. 